\title{
Merits and Demerits of Calcium Hydroxide as a Therapeutic Agent: A Review
}

\author{
Revathi. $\mathbf{N}^{1, *}$, Sharath Chandra S.M ${ }^{2}$ \\ ${ }^{1}$ Department of Conservative Dentistry, Krishnadevaraya College of Dental Sciences, Yelahanka, Bangalore \\ ${ }^{2}$ Department of Conservative dentistry and Endodontics, Krishnadevaraya College of Dental Sciences, Yelahanka, Bangalore \\ *Corresponding author: dr.revathi.natesan@gmail.com
}

Received October 11, 2014; Revised October 27, 2014; Accepted December 18, 2014

\begin{abstract}
Calcium hydroxide, an age-old, traditional, therapeutic agent, has found profound use in the field of conservative dentistry, endodontics, and pedodontics. It is indicated for vital pulp therapies, intracanal medication, endodontic sealing, pulp revascularization, apexification, and pulpotomy. The purpose of this review is to identify the various merits and demerits with regard to each application.
\end{abstract}

Keywords: calcium hydroxide, merits, demerits, vital pulp therapy, intracanal medicament, root resorption, review

Cite This Article: Revathi. N, and Sharath Chandra S.M, "Merits and Demerits of Calcium Hydroxide as a Therapeutic Agent: A Review.” International Journal of Dental Sciences and Research, vol. 2, no. 6B (2014): 14. doi: 10.12691/ijdsr-2-6B-1.

\section{Introduction}

Calcium hydroxide has been used in dentistry since several decades and has become a main-stay therapeutic agent owing to its numerous advantages. It has been used in a number of applications such as vital pulp therapy, pulp revascularization, apexogenesis, apexification, root resorption, intracanal medicament, and root canal sealers. Although this material exhibits several advantages, it also possesses some drawbacks. With regard to few applications, MTA is fast replacing calcium hydroxide as the material of choice. This review attempts to list the numerous applications of this classic therapeutic agent and the corresponding merits and demerits.

\section{Applications of Calcium Hydroxide}

\subsection{Vital Pulp Therapy}

This procedure includes pulp capping, partial pulpotomy, full pulpotomy, and pulpectomy.Pulp capping involves either direct or indirect (presence of a layer of intervening dentin) placement of calcium hydroxide on the pulp. Partial pulpotomy is also termed as Cvekpulpotomy. Here, inflamed coronal pulp tissue is removed but the healthy pulpal tissue is retained; the extent of pulp removal is based on a thorough knowledge of pulpal reactions post-injury. In full pulpotomy, the entire coronal pulp is removed up to the level of the orifices of the root. With regard to Pulpectomy, the entire pulp is removed, both from the coronal and the apical regions.

Calcium hydroxide as a vital pulp therapy agent:

With regard to this role, calcium hydroxide is one amongst the most preferred therapeutic agents. Since calcium hydroxide was introduced to endodontics as a pulp capping agent in 1920, it has gained popularity as a regenerative material and is widely used as on date. The following are the favourable properties that render calcium hydroxide as one amongst the most sought pulp regenerative agent.

(1) Antibacterial property

This property can be attributed to the release of the highly reactive hydroxyl ions whose mechanism of action can be ascribed to the following mechanisms: (1) destruction of the bacterial cytoplasmic membrane, (2) protein lysis, and (3) bacterial DNA damage. [1] It is effective against most endodontic pathogens [2].

(2) Mineralization property

This property can again be attributed to the hydroxyl ions, which induce an alkaline $\mathrm{pH}$. The high $\mathrm{pH}$ of 12.5 initially induces liquefaction necrosis in the superficial portion of the pulp $(1.5-2 \mathrm{~mm})$. This may eliminate the inflamed pulp if present. Further deeper portions of the pulp witness neutralization of the toxicity of calcium hydroxide so as to cause formation of a layer of tissue that undergoes coagulation necrosis at the junction of the necrotic and vital pulpal tissue. Beyond this portion, calcium hydroxide acts as a mild irritant, which stimulates hard tissue formation. [3] The calcified material is termed osteodentine since it exhibits the characteristics of both bone and dentin. An evidence-based study concluded that calcium hydroxide based materials promoted formation of a hard tissue bridge whereas bonding agents did not. In this regard, superiority of MTA over calcium hydroxidebased products was not confirmed either. [4] $\mathrm{CH}$ and MTAmay aid in hard tissue formation by solubilising dentinal growth factors, which in turn leads to the recruitment of pulpal stem cells. [5] Numerous studies have demonstrated dentinalbridge formation in about $50-87 \%$ of cases treated with various $\mathrm{Ca}(\mathrm{OH}) 2$ formulations [6]. 
Demerits: The barrier of osteodentine, which is produced, is often incomplete and results in the formation of the so-called tunnel defects. Formation of tunnel defects, which occur due to vascular inclusions may be observed in specimens treated with calcium hydroxide. Such defects may allow bacterial re-infection [7].

The 1.5-2mm layer of sterile pulp necrotic layer may get infected under leaking restorations thus causing pulpitis and subsequent pulp necrosis if left untreated [8].

Also, few authors have shown that MTA may be a superior material when compared to calcium hydroxide. According to Mente et al., MTA appeared to favour longterm pulp vitality after direct pulp capping when compared with calcium hydroxide [9].

After performing a histomorphometric analysis of pulp capping of human permanent premolars using calcium hydroxide and MTA, Maria et al. concluded that both the material were successful but calcium hydroxide was slower than MTA in this regard [10].

\subsection{Apexogenesis}

Apexogenesis is defined as a vital pulp therapy procedure performed to encourage continued physiologic development and formation of the root end [11].

The use of calcium hydroxide in traumatized immature tooth after complete chemomechanical debridement showed good results. Calcium hydroxide stimulated the epithelial cells of Hertwig's sheath and the undifferentiated progenitor cells and thus aided in continued apical root formation. [12] Its antibacterial property and inherent alkalinity are also beneficial.

Demerits:

Long-term usage of Calcium hydroxide may weaken the root.

\subsection{Apexification}

This procedure involves formation of a hard-tissue apical barrier and reinforcement of the thin dentinal walls of an immature non-vital tooth. It is defined as a method to induce a calcific barrier in a root with an open apex or the continued apical development of an incompletely formed root in teeth with necrotic pulp tissue. [11] Calcium hydroxide is used as a creamy mix to achieve canal disinfection. The hard tissue barrier formed with regard to long-term calcium hydroxide therapy comprises of irregularly arranged cementum-like tissue, soft tissue and calcified tissue. Islands of soft connective tissue interspersed within this barrier impart the characteristic 'Swiss cheese' consistency [13].

Demerits: The time taken for formation of a hard tissuebarrier with regard to calcium hydroxide, ranges from 2-3 months and 6-18 months in the case of pulp capping and apexification procedures respectively (3-5). This extended treatment time may inconvenience both the dentist and the patient. Calcium hydroxide affects the mechanical properties of dentin when used for a longer period of time rendering the tooth susceptible to fracture [14].

\subsection{Pulp Revascularization}

Revascularization is defined as the restoration of the vascularity to a tissue or organ. [11] Here, calicium hydroxide is primarily used to decontaminate the root canal system prior to inducing bleeding. Triple antibiotic paste has also been shown to be an effective agent in terms of eliminating root canal infection [15], but the minocycline component may induce tooth discoloration. [16] Cehreli et al. reported a case of successful revascularization with calcium hydroxide in immature necrotic molars after a follow-up of 10 months [17].

Adriana et al. proposed that the combination of calcium hydroxide and 2\% chlorhexidine gel may be used for revascularization of immature necrotic teeth since superior results could be obtained using the same [18].

Demerits:

Long-term use of calcium hydroxide may cause progressive calcification of the root canal space.[19] However, this is controversial.

\subsection{Root Canal Sealers}

Sealers are responsible for the principal functions of root fillings, which aim to prevent reinfection. That is, sealing the root canal system by entombing remaining bacteria and filling of irregularities in the prepared canal system. [20] Calcium hydroxide based sealers such as RealSeal, Sealapex, Apexit, and Apexit Plus have the advantage of Calcium hydroxide release, which in turn contributes to their antibacterial properties owing to the release of hydroxyl ions. They may also aid in the formation of root-end hard tissue.

Demerits:

Calcium hydroxide-basedsealers exhibit some disadvantages such as mild antibacterial properties, poor cohesive strength, greater solubility, and marginal leakage [21].

\subsection{Intra Canal Medicaments}

These are one amongst the other therapeutic agents that aid in the elimination of microorganisms, their byproducts, and residual tissue from the canal system. [22] According to Weine, a medicament is an antimicrobial agent that is placed inside the root canal between treatment appointments in an attempt to destroy remaining microorganisms and prevent reinfection [23].

Demerits:

Calcium hydroxide has been shown to be less effective against Enterococcus faecalis and Candida albicans. [24] The literature on biocompatibility of calcium hydroxide especially when extruded into the periapical region is ambiguous with some reports endorsing its tolerance. $[25,26,27]$ and some rejecting it $[28,29]$.

\subsection{Perforation Management}

Calcium hydroxide was the most preferred material for the management of root perforations. In 1987, Bramante et al observed that experimentally prepared furcal root perforations in dog's maxillary and mandibular premolars showed better results when treated with calcium hydroxide. A zone of necrosis was observed immediatelyadjacent to the perforation site along with different degrees of cementum hyperplasia. Whereas, specimens dressed with zinc oxide and eugenol exhibited inflammatory reactions followed with abscess formation and alveolar crest resorption [30].

Demerits: 
Calcium hydroxide has to be replaced on a regular basis since (1) it is displaced by tissue fluids, exhibits poor marginal integrity, and (3) lacks the required strength. [31] It is hence a temporary solution and the newer materials like MTA have gained popularity as a more permanent solution.

Root resorption

The acidic environment existing in the region of resorption is neutralized by the alkaline calcium hydroxide leading to a reversal of reaction andthus allowing hard tissue formation.[32]The hydroxyl ions released by calcium hydroxide diffuse through dentinal tubules that directly communicate with periodontal space, whose $\mathrm{pH}$ after the ion infusion, increases from 6.0 to 7.4-9.6[33]. Apart from the above mentioned factor, the other important properties of calcium hydroxide that may contribute to treatment of resorption include: bactericidal, protein denaturing, and adenosine triphosphatase activating properties. Calcium hydroxide can also arrest inflammatory root resorption [34].

A study that histologically examined the healing of intentionally produced inflammatory root resorption of replanted teeth in beagle dogs concluded that long-term treatment usingcalcium hydroxide was more effective than the short-term treatment in cases of established inflammatory root resorption [35].

Demerits:

Ironically, the use of calcium hydroxide in deciduous teeth is discouraged since it may induce chronic pulpal inflammation and internal root resorption [36].

According to Ravi et al., calcium hydroxide-induced resorption in deciduous teeth may be attributed to: (1) inflammatory cytokines, which contribute to transformation of pre-odontoclasts to odontoclasts (2) preexisting progenitor cells with a tendency to transform into odontoclasts, and loss of protective layer of predentin over mineralized dentin [37].

\section{Conclusion}

The applications of calcium hydroxide in the field of dentistry have been numerous. Its high alkalinity has contributed to its antibacterial and hard tissue forming properties. However, the lack of effectiveness against certain bacteria, solubility in fluids, poor coronal seal and strength are some concerns that need to be addressed. Also further research has to be undertaken in terms of improving and ascertaining the properties of calcium hydroxide.

\section{References}

[1] Siqueira JF, Lopes HP, "Mechanisms of antimicrobial activity of calcium hydroxide: a critical review,”International Endodontic Journal, 32, 361-9, 1999.

[2] Mohammadi Z, Dummer P.M.H., "Properties and applications of calcium hydroxide in endodontics and dental traumatology,” International Endodontic Journal, 44, 697-730, 2011.

[3] H.R. Stanley, T. Lundy, “Dycal for pulp exposures,”Oral Surgery Oral Medicine Oral Pathology, 34(5), 818-27,1972.

[4] Fransson H,“On the repair of the dentine barrier,”Swed Dent J Suppl. 226, 9-84, 2012.

[5] Graham L., Cooper P., Cassidy N., Nor J.E., Sloan A.J., Smith A.J., "The effect of calcium hydroxide on solubilisation of bio- active dentine matrix components.”Biomaterials, 27, 2865-73, 2006.

[6] Hargreaves K.M., Goodis H.E., and Seltzer,"MTA versus calcium hydroxide as a pulp capping agent," Chicago: Quintessence Publishing, 19, 227-245, 2002.

[7] Cox C., Subay R., Ostro E., Suzuki S., Suzuki S.H., “Tunnel defects in dental bridges: their formation following direct pulp capping”, Oper Dent, 21, 4-11, 1996.

[8] Schro"der U., Granath L.E., "Early reaction of intact human teeth to calcium hydroxide following experimental pulpotomy and its significance to the development of hard tissue barrier”, Odontol Revy, 22, 379-96, 1971.

[9] Mente J, Geletneky B, Ohle M, Koch MJ, Friedrich Ding PG, Wolff D, Dreyhaupt J, Martin N, Staehle HJ, Pfefferle T. "Mineral trioxide aggregate or calcium hydroxide direct pulp capping: an analysis of the clinical treatment outcome", Journal of Endodontics. 36(5), 806-13, May, 2010.

[10] Maria de Lourdes R, Accorinte, RobertoHolland, AlessandraReis, Marcelo C. Bortoluzzi,Sueli S. Murata,Elo yDezan, ValdirSouza, LoguercioDourado Alessandro, "Evaluation of Mineral Trioxide Aggregate and Calcium Hydroxide Cement as Pulp-capping Agents in Human Teeth”, Journal of Endodontics, 34(1), January 2008.

[11] Kenneth M. Hargreaves and Stephen Cohen, Pathways of the pulp, Elsevier, $10^{\text {th }}$ edition, 2011, 608-637, 650.

[12] Saad AY, “Calcium hydroxide and apexogenesis”, Oral Surg Oral Med Oral Pathol. 66(4), 499-501, Oct,1988.

[13] Bortoluzzi EA, BroonNJ, Bramante CM, Consolaro A, Garcia RB, de Moraes IG, Bernadineli N. "Mineral Trioxide Aggregate with or without Calcium Chloride in Pulpotomy”, J Endod. 34(2), 172-5, Feb, 2008.

[14] Grigoratos D, Knowles J, Ng YL, Hulabivala K. "Effect of exposing dentine to sodium hypochlorite and calcium hydroxide on its flexural strength and elastic modulus”, IntEndod J, 34, 1139, 2001.

[15] Cotti E, Mereu M, Lusso D. "Regenerative treatment of an immature, traumatized tooth with apical periodontitis: Report of a case”, J Endod, 34, 611-6, 2008.

[16] Dabbagh B, Alvaro E, Vu DD, Rizkallah J, Schwartz S. “Clinical complications in the revascularization of immature necrotic permanent teeth”. Pediatr Dent, 34, 414-7, 2012.

[17] Cehreli ZC, Isbitiren B, Sara S, Erbas G, J Endod.37(9), 1327-30, Sep, 2011.

[18] Adriana de Jesus Soares, Fernanda FreitasLins, Juliana Yuri Nagata, Brenda Paula Figueiredo de Almeida Gomes, Alexandre Augusto Zaia, CaioCezar Randi Ferraz, José FlávioAffonso de Almeida, and Francisco José de Souza-Filho, "Pulp Revascularization after Root Canal Decontamination with Calcium Hydroxide and 2\% Chlorhexidine Gel, Journal of Endodontics”, 39(3), 417-420, March 2013.

[19] Chueh LH, Ho YC, Kuo TC, Lai WH, Chen YH, Chiang CP. "Regenerative endodontic treatment for necrotic immature permanent teeth”. J Endod, 35, 160-4, 2009.

[20] Ørstavik D,“Materials used for root canal obturation: technical, biological and clinical testing”, Endodontic Topics, 12, 25-38, 2005.

[21] Shalin Desai, Nicholas Chandler, "Calcium Hydroxide-Based Root Canal Sealers: A Review”, J Endod, 1-6, 2009.

[22] Mohammadi Z, Dummer PMH."Properties and applications of calcium hydroxide in endodontics and dental traumatology". International Endodontic Journal, 44, 697-730, 2011.

[23] Weine FS,Endodontic therapy, 6th edn.2004, Mosby, pp. 226-8.

[24] Mohammadi Z, Dummer PMH."Properties and applications of calcium hydroxide in endodontics and dental traumatology". International Endodontic Journal, 44, 697-730, 2011.

[25] Martin DM, Crabb HS.Br Dent J. 3,142(9):277-83, May, 1977.

[26] Guigand M, Pellen-Mussi P, Le Goff A, Vulcain JM, BonnaureMallet $\mathrm{M}$, "Reaction of bony tissue to implanted root canal filling material in guinea pigs”. OdontologiskTidskrift,77, 133-59, 1999.

[27] Martine Guigand, Pascal Pellen-Mussi, Anne Le Goff, Jean-Marie Vulcain, Martine Bonnaure-Mallet, "Evaluation of the cytocompatibility of three endodontic materials".Journal of Endodontics, 25(6), 419-23.

[28] Hauman CH, Love RM, "Biocompatibility of dental materials used in contemporary endodontic therapy: a review” Part 1. Intracanal drugs and substances. Int Endod J. 36, 75-85, 2003. 
[29] Blomlöf L, Lindskog S, Hammarstrom L, "Influence of pulpal treatments on cell and tissue reactions in the marginal periodontium”, Journal of Periodontology 59, 577-83, 1988.

[30] Clóvis Monteiro Bramante, Alceu Berbert, "Root perforations dressed with calcium hydroxide or zinc oxide and eugenol", Journal of Endodontics13(8), 392-395, August 1987.

[31] Schuurs AH. Gruythusen RJ, Wesserlink PR., "pulp capping with adhesive resin-based composite vs. calcium hydroxide:a review", Endodontics and Dental Traumatology 16, 240-50, 2000.

[32] Esberard RM, Carnes DL, Del Rio CE," $\mathrm{pH}$ changes at the surface of root dentin when using root canal sealers containing calcium hydroxide", Journal of Endodontics 22, 399-401, 1996a.

[33] Tronstad L, Andreason J O, Hasselgren G, Kristerson L, Riis I. "PH changes in dental tissues after root canal filling with calcium hydroxide”. J Endod,; 7: 17-21, 1981.
[34] TronstadL.Rootresorption--etiology, "terminology and clinical manifestations” Endod Dent Traumatol. 4(6):241-52, Dec,1988.

[35] Trope M, Moshonov J, Nissan R, Buxt P, Yesilsoy C. "Short vs. long-term calcium hydroxide treatment of established inflammatory root resorption in replanted dog teeth.Endod Dent Traumatol.” 11(3):124-8, Jun, 1995.

[36] Magnusson B. "Therapeutic pulpotomy in primary molars-Clinical and histological follow-up,” Odontol Revy, 21, 415-31, 1970.

[37] GR Ravi, RV Subramanyam, "Calcium hydroxide-induced resorption of deciduous teeth: A possible explanation”, Endod Dent Traumatol. 4(6), 241-52, Dec, 1988. 